\title{
AYMARAS Y PLEBISCITARIOS. LOS INDÍGENAS ANDINOS, LA CHILENIZACIÓN Y LAS IDENTIDADES EN LA FRONTERA CULTURAL (PUTRE $1920-1929)^{*}$
}

\author{
Aymaras and plebiscites. Andean Indigenous, the chilenización and \\ identities in the cultural border. (Putre 1920-1929)
}

\author{
Alberto Díaz ${ }^{* *}$ \\ Luis Galdames ${ }^{* * *}$ \\ Rodrigo Ruz ${ }^{* * * *}$
}

Recibido: 4 de noviembre de 2012. Aprobado: 9 de abril de 2013.

\section{RESUMEN}

Este artículo analiza, sobre la base de documentación archivística, cómo las poblaciones indígenas aymaras del extremo norte de Chile asumieron identidades nacionales peruanas, en contraposición a las políticas de "chilenización" implementadas tanto por las agencias como los agentes chilenos en los poblados de la cordillera andina de Arica, ad portas del plebiscito pactado para 1926. Se examinan antecedentes cuantitativos (censos) y testimonios asociados a violencia y xenofobia en torno a la construcción de lealtades nacionales en la periferia de Putre y la frontera de los países andinos.

PALABRAS CLAVES: Aymaras, plebiscito, chilenización.

Este artículo es resultado de la investigación del Proyecto Fondecyt № 1110965 y del proyecto de Investigación Mayor de Ciencia y Tecnología de la Universidad de Tarapacá. Código 5710-12. Asimismo, se agradece el apoyo del Convenio de Desempeño Universidad de Tarapacá-Mineduc.

** Universidad de Tarapacá, Departamento de Ciencias Históricas y Geográficas, Arica, Chile. Correo electrónico: albertodiaz@uta.cl

*** Universidad de Tarapacá, Departamento de Ciencias Históricas y Geográficas, Arica, Chile. Correo electrónico: lgaldame@uta.cl

**** Universidad de Tarapacá, Departamento de Ciencias Históricas y Geográficas, Arica, Chile. Correo electrónico: rruz@uta.cl 


\begin{abstract}
Utilizing archival documentation, this paper analyzes how the indigenous Aymara of Northern Chile took on Peruvian national identities, in opposition to the policies of "chilenization" implemented by both agencies and Chilean agents in the villages of the Andean Mountains of Arica, right before the plebiscite agreed upon in 1926. It examines quantitative data (census) and testimonies associated to violence and xenophobia related to the construction of national loyalties in the periphery of Putre and the border of the Andean countries.
\end{abstract}

KEY WORDS: Aymara, Plebiscite (o Referendum), Chilenization.

\title{
I. INTRODUCCIÓN
}

El 20 de octubre de 1883, fecha en la cual se firma el Tratado de Ancón entre Perú y Chile, los territorios de Tacna y Arica pasaron a la administración chilena por un plazo de 10 años, tiempo en que un protocolo establecería las condiciones burocráticas para materializar un acto plebiscitario entre la población local. Elección que decidiría a qué país correspondería la soberanía de dichas provincias (González 2008; Calderón 2000). Por lo tanto, era la sociedad regional que resolvería los destinos soberanos de dichos territorios, incluyendo a los indígenas que para entonces, no dudaron en manifestar sus compromisos ciudadanos a favor del Perú (Díaz, Galdames y Ruz 2010). En tanto, existieron diversos intentos por alcanzar una salida diplomática al litigio, aunque las propuestas se frustraron una y otra vez, por lo que la planificación del evento plebiscitario fue perdiendo validez como instrumento resolutivo, debido a que al parecer no existía una total disposición de las partes para fijar una fecha para el sufragio (Calderón 2000; Yepes 1999).

Sin embargo, la historia fue otra. El mencionado plebiscito nunca logró materializarse, generando un clima caracterizado por el conflicto de identidades nacionales y estallidos de violencia entre la población de Tacna, Tarata o Arica, como en los poblados de la sierra o del altiplano andino. Puntualizando, el Estado chileno tempranamente había implementado una administración con el fin de ejercer un control soberano de la zona y desplegar una serie de estrategias para "chilenizar" el territorio, lo que permitiría -en teoría- que la población votara a favor de Chile. Hubo ocasiones, sobre todo en momentos cercanos al pactado evento electoral (principalmente para 1926, última fecha estimada por el árbitro internacional para el sufragio), donde los sentimientos nacionales se exte- 
riorizaban con mayor euforia, creando una atmósfera de violencia ciudadana entre los bandos peruanos y chilenos, lo que también se tradujo en distintos tipos de alteraciones al orden público (Díaz 2006; González 2004a; Palacios 1974).

Durante todo este período, las agencias y agentes gubernamentales orientaron su accionar en establecer una estructura política, sostenida en el control social y en la reproducción de los valores e imaginarios nacionales chilenos. Desde una perspectiva teórica, la exaltación de los símbolos patrios, la aplicación de un ordenamiento jurídico, la instauración de su aparataje burocrático y militar, además del sistema escolar, los clérigos o empleados civiles, operaron (al parecer) bajo la lógica de "integrar a todos" mediante diferentes estrategias para reproducir la comunidad imaginada, con sus tradiciones y emblemas (Anderson 2000; Hobsbawm y Ranger 2002; Gellner 1983). En definitiva, con la aplicación de políticas consecuentes a intereses geopolíticos, incluso con un marcado sesgo xenofóbico, se buscó nacionalizar el territorio con fines electorales y "soberanos". Este período ha sido denominado como la "chilenización" de los territorios integrados a la soberanía nacional tras la guerra del Pacífico (Gundermann 1998).

Hacia la década de 1920 se evidenció un notable aumento de la población chilena en el área de Arica, lo que habría permitido al Estado aparentemente triunfar en el plebiscito programado definitivamente para 1926. Puntualizando, el censo de 1917 arrojó los siguientes datos: 5.308 (41,23 por ciento) chilenos; 5.627 (43,71 por ciento) peruanos; 1.374 (10,67 por ciento) bolivianos, y 562 (4,36 por ciento) de otras nacionalidades, con un total de población de 12.871 (Archivo Histórico Vicente Dagnino 1917), lo que demuestra que el número de chilenos se equiparaba al segmento peruano, significando un escenario electoral bajo un "empate técnico". Pero, en torno a los comuneros andinos reconocidos étnicamente como aymaras, con una larga presencia histórica en la cordillera ariqueña, cabe advertir: ¿cuáles eran las definiciones identitarias nacionales en un contexto electoral sociopolítico asumidas por este grupo étnico habitante de los espacios rurales? En el siguiente cuadro es posible constatar con mayor magnitud la presencia de distintas nacionalidades en las subdelegaciones rurales del área de Arica: 


\section{Cuadro No 1}

Porcentaje de población de las subdelegaciones rurales de la provincia de Arica, con derecho a voto (1924)

\begin{tabular}{|c|c|c|c|c|c|}
\hline Distrito censal & Peruanos & Chilenos & Bolivianos & Extranjeros $^{1}$ & Total \\
\hline Lluta & 16.6 & 82.9 & 0.3 & 0.2 & 100.0 \\
\hline Azapa & 22.6 & 51.9 & 10.4 & 15.1 & 100.0 \\
\hline Belén & 84.1 & 3.7 & 12.2 & ------ & 100.0 \\
\hline Codpa & 86.4 & 4.5 & 8.2 & 0.9 & 100.0 \\
\hline Putre & 67.7 & 3.6 & 27.8 & 0.9 & 100.0 \\
\hline General Lagos & 45.3 & 37.5 & 14.1 & 3.1 & 100.0 \\
\hline
\end{tabular}

Fuente: Cuadro elaborado en base a la información contenida en el Archivo (Ministerio de Relaciones Exteriores del Perú 1925: 438).

Los registros subrayan que existe un significativo número de indígenas andinos que se adscribe a la nacionalidad peruana, la cual se concentra en los poblados serranos de Putre, Belén o Codpa en el hinterland o región circundante de Arica, ¿acaso los aymaras estaban asumiendo compromisos sociopolíticos en favor del Perú, como oposición a la presencia de las agencias estatales chilenas? Como es de suponer, el cuadro anterior describe cuantitativamente esa intención electoral de los indígenas ${ }^{1}$. La discusión ha intentado visualizar a los indígenas reconocidos étnicamente como aymaras, en escenarios históricos complejos en materia sociopolítica, relevando sus compromisos nacionales y la participación en los distintos dispositivos que los Estados nacionales han establecido en la zona. Sobre el panorama étnico de las zonas rurales de Arica durante las primeras décadas del siglo XX, hemos insistido previamente sobre la condición cultural, lingüística e identitaria de los aymaras, y cómo estos han sido a su vez descritos por los agentes gubernamentales de la época (Díaz y Ruz 2009). Al respecto podemos volver a citar el siguiente manuscrito:

La población de la provincia de Tacna (departamentos de Tacna y Arica) tiene una composición étnica que difiere de la del resto de la República [...]. De raza indígena americana, o mestiza, son la mayoría de los 15.000 bolivianos y 12.000 peruanos que habitan el país. Los extranjeros provenientes de otros países americanos o de Europa son de raza blanca. En la provincia de Tacna la situación es muy diversa, pudiendo distinguirse

1 En una serie de trabajos anteriores, hemos problematizado la participación de los segmentos indígenas del área de Arica, tanto en los contextos republicanos peruanos como en los procesos de incorporación nacional a Chile (Díaz 2006; Díaz, Galdames y Ruz 2010). 
claramente en su población cuatro razas diversas, a saber: a) raza blanca; b) raza indígena; c) raza negra, y d) raza mestiza. [...] b). Los indígenas forman casi la totalidad de la población en las regiones del interior de la provincia. Estos indígenas pertenecen a la raza aymará, que, junto con los "atacamas" y los "quechuas", forman la rama de los "peruvianos" de la familia indígena llamada "andina" [...]. Forman parte, en consecuencia, de esa raza, los indígenas de la provincia de Tacna, y los que se encuentran en el interior de la provincia de Tarapacá. La inmensa mayoría, de la casi totalidad de la población de las subdelegaciones de Tarata y Palca, del departamento de Tacna, y de las de General Lagos, Putre, Belén y Codpa, del departamento de Arica, está constituida por estos indios de raza aymará. Todos esos indígenas hablan el idioma aymará. Los que habitan la parte más oriental de la provincia, es decir, el distrito de Mauri, la subdelegación de General Lagos y las regiones del departamento de Arica que limitan con Bolivia, hablan exclusivamente esa lengua, sin que se haya difundido entre ellos el idioma español. Esto se debe al hecho de que allí no hay centros de población, sino que los indios viven aislados, a grandes distancias unos de otros, dedicados al pastoreo de sus llamas y alpacas. Los indígenas de las regiones de las quebradas que se extienden al poniente de la altiplanicie, es decir, los habitantes de las subdelegaciones de Tarata (menos el distrito de Mauri), y de Palca, del departamento de Tacna, y de la parte occidental de las subdelegaciones de Putre, Belén y Codpa, del departamento de Arica, que viven agrupados en aldeas y caseríos, y que tienen contacto constante con los habitantes de las ciudades de Tacna y Arica, hablan el idioma castellano; pero todos ellos practican también su idioma indígena, y se encuentran numerosos individuos, sobre todo entre las mujeres, que no conocen otra lengua que ésta (Barceló 1924: 777-82).

Siguiendo estos antecedentes es plausible preguntarse: ¿no había surtido efecto la chilenización en los poblados de la cordillera de los Andes, que los indígenas aymaras asumían otros compromisos nacionales? Esta interrogante permite canalizar los temas que este artículo problematiza sobre el pasado del norte del país, discutiendo sobre la base de antecedentes archivísticos y bibliografía de la época, cómo participaron los comuneros aymaras en las diferentes estructuras sociopolíticas (como el sufragio) que el Estado chileno implementó en la zona andina de Arica, amén de identidades y lealtades nacionales friccionadas (y fracturadas) al construirse una frontera cultural en el actual extremo norte chileno.

\section{UN AMBIENTE EN CALMA}

El 15 de enero de 1888 desde la prefectura general del departamento de Tacna, localizada en Sama, el prefecto Varela envió una misiva al director general del Gobierno, 
exponiendo: "Tengo el agrado de participar a Ud. que el orden público se conserva inalterable en todo el territorio de mi dependencia" (Archivo General de la Nación 1888). Lo interesante de aquel diagnóstico es que en la zona de Tacna, Arica y sus alrededores, donde supuestamente debían esperarse condiciones socialmente hostiles, aquello no acontecía. De hecho, Varela describe que en la región se posa un "orden inalterable", y aún más, este tipo de relatos se repite en múltiples ocasiones.

Esta nota podría evidenciar que durante los primeros años de la ocupación chilena, no necesariamente se constituyó un ambiente de disonancia política y social, quizás, debido a la posibilidad de que las provincias en conflicto volverían a formar parte, en virtud de un plebiscito, a la República peruana. Ciertamente, es una circunstancia disímil si la comparamos con lo sucedido en Tarapacá, territorio que automáticamente se anexó al territorio y soberanía chilena. De acuerdo a los antecedentes que disponemos, tanto en Tacna como en Arica durante este período se generaron lazos de sociabilidad entre peruanos y chilenos, que salvo excepciones (relacionadas con coyunturas de las negociaciones diplomáticas o las conductas de las autoridades locales), mantuvieron un escenario caracterizado por una relativa tranquilidad social (Díaz 2006).

$\mathrm{Al}$ respecto, Palacios expone que estos intervalos de paz responderían a un tipo de chilenización diseñada para procurar "el orden material, que aparentemente podría beneficiar a los habitantes de esa región" (Palacios 1974: 55), contrariando así de una chilenización violenta ${ }^{2}$. Vial Solar (1900) tempranamente señaló que la chilenización en las provincias de Tacna y Arica durante los primeros años consistió en "una serie de medidas que sin violencia hicieran simpático a sus habitantes el nuevo orden político a que su voluntad debía someterlos" (Vial Solar 1900: 56). Pese a aquello, existieron reclamos debido a que la administración diferenció entre la población chilena y la peruana para la asignación de beneficios. Un ejemplo corresponde a una nota del intendente chileno de Tacna, Emilio Bello, el cual en 1904 informa que el Congreso aprobó realizar obras públicas y otros adelantos en Tacna, recomendando la compra de terrenos para ser entregados solo a la población de origen chileno (Archivo Histórico Vicente Dagnino 1904).

Tras el fracaso en la materialización del plebiscito de 1894 (y la postergación de este), se reorientaron las prácticas burocráticas chilenas, con el objetivo de que en el futuro (incierto por lo demás), se intentaría ganar al electorado. De hecho, para 1900 se

2 De acuerdo a este autor, la "chilenización pacífica" finaliza luego que Chile resuelve el problema limítrofe con Argentina, iniciándose así a partir de 1900 una "chilenización violenta". Para la zona de Tarapacá, González (1994) también identifica un momento de recrudecimiento de la chilenización, tildada como "compulsiva", pero iniciada hacia 1910. 
denota un claro giro en la intencionalidad de las prácticas de las agencias plebiscitarias. Pero, ¿será este cambio en la praxis sociopolítica lo que puede ser consignado como un programa "chilenizador"? Los supuestos chilenizadores apuntan a una campaña electoral y a una estrategia por unificar criterios burocráticos que no alteraran las razones de fondo de la presencia chilena en la región, cuyo fin pretendía consolidar la soberanía y garantizar el dominio imperioso de la provincia vecina de Tarapacá (zona donde se localizaban los yacimientos de salitre). En tal sentido, un aviso de un policía del pueblo de Putre, fechado en 1905, apunta con alarma que el subdelegado rural abandonó su cargo, por lo que se temía que los indígenas se sublevaran, creyendo que habían conseguido su anhelo: “¡No más administración chilena!” (Archivo Histórico Vicente Dagnino 1905).

$\mathrm{Al}$ año siguiente, los putreños solicitaron izar la bandera peruana motivados por la celebración de sus fiestas patrias, para lo cual se acercaron al jefe de policía, para requerir el enarbolado del pabellón, lo que obviamente fue prohibido. La bandera, como símbolo de la nación, podía ser considerada como un gesto de agitación nacionalista properuana. El argumento para evitar su uso fue que únicamente las autoridades consulares podían alzar banderas de otras naciones, y no los vecinos. El hecho no es menor si pensamos que la solicitud no provenía de autoridad alguna, sino de los propios comuneros, dando cuenta que dichas festividades cívicas actuaron como dispositivos que permitieron catalizar las antiguas identidades en una zona friccionada por las lealtades nacionales (Díaz, Galdames y Ruiz 2010).

Los aislados hechos relatados corresponden a sucesos parcialmente conflictivos anteriores a 1920; fecha relevante, ya que se erige como un punto de inflexión debido al acercamiento diplomático entre las partes beligerantes; pero al mismo tiempo, 1920 reinaugura las coyunturas políticas y las fricciones identitarias entre los actores locales en una frontera cada vez más compleja. Al unísono, dos novedades se sumarán al debate: primero, los apremios o demandas nacionales ya no corresponderán a hechos aislados, sino que aquellos actos se pueden evaluar como un conjunto coherente de olas o embates de violencia política; y en segundo lugar, la participación civil tendrá mayor significación en el desarrollo de los acontecimientos, gravitando la tensión social y la violencia xenofóbica (González 2008).

\section{PLEBISCITO Y FRICCIÓN SOCIAL (1920-1924)}

La década de 1920 se constituye como un escenario sociohistórico que marcó las tensas relaciones sociales experimentadas por la población de las "provincias cautivas" de 
Arica y Tacna, debido al incremento de una serie de hechos violentos, amén de la materialización del plebiscito pactado en definitiva para 1926. Situaciones tensionales como altercados, expulsiones y enfrentamientos entre los bandos caracterizaron el preludio de la consulta popular; por tales motivos, es posible argumentar que la atmósfera electoral implicó una discontinuidad en el ambiente de aparente sociabilidad que impregnaron anteriormente los primeros años de la ocupación chilena. Sin perjuicio de lo anterior, existían evidentes conflictos que paulatinamente fisuraron las interacciones entre actores locales peruanos (indígenas para el caso de estudio) y los agentes gubernamentales chilenos.

Un actor invitado a este entablado fue Estados Unidos, que se posicionó sobre un aparato negociador establecido en Washington, extendiéndose hasta Tacna y Arica por comisiones visitantes encabezadas primeramente por el general Pershing y, después por la misión que acompañó al estadista Lassiter. Esta última, al evaluar la situación regional, instituyó las condiciones políticas para la aplicación de los escrutinios según los preceptos originales del Acuerdo de Ancón de 1883. Se adoptaron entonces disposiciones de quiénes tendrían derecho a voto, lugares de sufragio, mesas inscriptoras, entre otros aspectos atingentes a las votaciones.

El arribo de los observadores norteamericanos generó preocupación entre las autoridades chilenas, despertando también el interés de la población peruana por defender posiciones identitarias nacionales implicadas. De este modo, conjeturamos que a partir de 1920 se fracturan los lazos que propiciaron el relativo escenario pasivo de las décadas precedentes. Esta fisura de las relaciones políticas es posible advertirla en torno a las celebraciones públicas de las fiestas patrias peruanas, siendo prohibidas a partir de 1921 en toda la subdelegación de Putre las manifestaciones patrióticas peruanas como el izar banderas albirrojas (Archivo de la Subdelegación de Putre 1921). Como en las décadas pasadas, el acto de prohibir el izamiento de los emblemas nacionales para una conmemoración de tal naturaleza gatilló el descontento entre los comuneros, escenario que contrastaba con múltiples banderas chilenas en las reparticiones públicas y escuelas de la sierra; inclusive, los locales educacionales fueron utilizados para la venta y distribución de banderines tricolores en todas las comarcas (Archivo de la Subdelegación de Putre 1921). Como ya inferimos, la bandera como símbolo podía constituirse en un indicador de las intencionalidades de los electores de la sierra y altiplano de Arica. La preocupación por la presencia de banderas chilenas (y también peruanas), se constata en la circular $\mathrm{n}^{\circ} 604$ del 26 de mayo de 1922 de la Gobernación; en esta se informa que todas las subdelegaciones debían informar a la brevedad sobre el número de banderas que existen, e investigar a los lugareños para "saber sus intereses patrios" (Archivo de la Subdelegación de Putre 1922a). 
En 1922, llegó como capellán de la iglesia de Putre el sacerdote español Domingo Martínez Gago, nombrado por el vicario castrense de Arica, monseñor Rafael Edwards. Después de una visita a los distintos caseríos y poblados andinos, y tras entrevistarse con los vecinos, denunció atropellos sobre los "nativos peruanos" en las aldeas. Agrega, "venían a decírmelo, confiando en mi calidad de español. Yo les escuchaba y sentía temblar mis carnes de horror. Vi muchos". Asimismo, este cura informó sobre la condición de la parroquia luego de la expulsión de los sacerdotes peruanos a partir de 1911, en la cual "no se administraba allí los sacramentos, ni se oficiaba misa. Yo tuve que desenvolver los Sagrados Objetos, tal como lo habían dejado los peruanos" (Revista Mundial 1925). Meses después, Martínez fue cesado de sus funciones.

Consignemos que Rafael Edwards solo poseía jurisprudencia eclesiástica ante las tropas militares chilenas, al ser vicario castrense. Sus prédicas y acciones se regulaban bajo ese formato, ya que la administración del culto aún se encontraba bajo la jurisdicción del obispo franciscano de Arequipa, fray Mariano Olguín (Documentos relativos al plebiscito de Tacna y Arica 1926a). Esta ambivalencia generó problemas en el campo religioso, ya que pese a las expulsiones de algunos sacerdotes peruanos, otros aún continuaron realizando liturgias y celebraciones en oratorios públicos y privados de la sierra (Documentos relativos al plebiscito de Tacna y Arica 1926b).

Aquel año (1922), los agentes chilenos enfatizaron con propaganda los beneficios de su administración, destacando los avances en infraestructura, higiene y salubridad pública. Además, existía cierta inquietud entre las autoridades chilenas por la propagación de las ideas peruanas entre los lugareños, tanto así que el 21 de octubre el subdelegado de Putre informó de la conveniencia que significaba que los cargos de contacto directo con la comunidad fueran asumidos por chilenos (Archivo de la Subdelegación de Putre 1922-1923a). En el mismo tenor, el 4 de mayo de 1922, la Junta de Alcaldes de Arica decidió cambiar los nombres de las calles de Putre por denominaciones que hacían directa alusión a héroes patrios chilenos, eliminando los antiguos nombres de origen peruano (Archivo de la Subdelegación de Putre 1922-1923b). También fue una preocupación el control de la población que ingresaba y salía por los pasos fronterizos, buscando impedir la entrada al territorio de individuos sospechosos con propaganda peruana, cuya documentación no estuviera rotulada según la normativa chilena, incluyendo a la población boliviana (Archivo de la Subdelegación de Putre 1922b).

Tales disposiciones pueden ser comprendidas ante la posibilidad del sufragio para los extranjeros, los que eventualmente podían llegar a ser "residentes" con derecho a voto. Por lo anterior, se dispuso el retiro de los extranjeros contrarios a las ideas chilenas, y 
simultáneamente, la permanencia de aquellos que favorecían aquella causa. Con tal objetivo, a partir de 1921 se evaluó la preferencia electoral de los extranjeros y de la población local, encuesta (si es que así es posible denominarla) que fue conocida en aquel momento como "el censo sentimental".

El 2 de noviembre de 1922, el gobernador de Arica Emiliano Bustos protocolizó la actualización los datos del "censo sentimental". En el oficio se expone como pretexto hacer una "vacunación contra la viruela en los valles y la sierra", verificando los datos del censo y las intencionalidades del electorado, para actualizar los datos del año anterior (Archivo de la Subdelegación de Putre 1922c). El 28 de marzo de 1923, el gobernador manifestó que era necesario manejar el número exacto de pobladores de la región, recomendó a los agentes tener "mucho cuidado de dichos sentimientos identitarios" de los nativos. Se debían constatar, arguye, las tendencias o simpatías de los votantes, en particular de los hombres mayores de 17 años (Archivo de la Subdelegación de Putre 1923a), configurándose paulatinamente una sociedad panóptica en la cordillera andina de Arica.

La tensión social generada en el altiplano se puede constatar en localidades como Caquena, poblado donde el inspector distrital solicitó al subdelegado de Putre, el 27 de octubre de 1923, la eliminación del cargo de comisario del pueblo ejercido por Mariano Gutiérrez, argumentando la total pérdida de confianza sobre este comunero, ya que mantenía vínculos con los ciudadanos peruanos. En su reemplazo, solicitó la participación de Domingo Yucra Olave, exaltando sus sentimientos chilenos (Archivo de la Subdelegación de Putre 1922-1923c). Meses antes, el 7 de febrero, el gobernador informó al subdelegado que la autorización a Martín Apaz Choque para explotar yareta, solo se realizaría ante una respuesta satisfactoria según tres puntos claves: la extensión del territorio, la nacionalidad y los sentimientos patrios de este (Archivo de la Subdelegación de Putre 19221923d). Sobre el mismo tema, el 30 enero de 1923, el subdelegado había comunicado al gobernador sobre una solicitud de Leonardo Rocha Orozco, del pueblo de Parinacota, el cual requería una concesión fiscal; pero esta debía ser denegada, ya que Rocha era un comunero pernicioso para la causa chilena (Archivo de la Subdelegación de Putre 1923b). Del mismo modo, se objetaba la autorización para realizar algún tipo de actividades o que los comuneros que no justificaran la nacionalidad chilena accedieran a cargos públicos y a beneficios (Archivo de la Subdelegación de Putre 1922-1923d).

El 25 de septiembre de 1923, el gobernador instruyó a todos los oficiales sobre la necesidad de fortalecer las fiestas patrias en Putre, para lo cual envió dos ejemplares del periódico El Ferrocarril, informando de los actos celebrados en la subdelegación rural de Azapa, destacando que era la primera vez que los "regnícolas" 
("nativos") del valle concurrían masivamente a la conmemoración de la fiesta del 18 de septiembre, lo que significaba que los "regnícolas" de Azapa habían llegado al convencimiento de que la soberanía chilena se afianzaría en forma definitiva. La exhortación concluía diciendo:

es menester que Ud. obtenga el mayor provecho posible de esta actitud de los habitantes del valle más cercano a Arica, haciendo ver a los vecinos de esa Subdelegación el significado que tiene su concurrencia a nuestra fiesta nacional en las proximidades del plebiscito. Por medio de una propaganda discreta. Ud. puede hacer valer ante ellos esto hecho, como la prueba más elocuente de que el triunfo de nuestros derechos está asegurado (Archivo de la Subdelegación de Putre 1923c).

En este pulso temporal, las autoridades enfatizaron las celebraciones cívicas, conmemorando a los héroes chilenos como una tónica central de la campaña electoral, enfatizando las asimetrías entre las interacciones de los bandos peruanos y chilenos (Archivo de la Subdelegación de Putre 1924). Así, el subdelegado de Putre, el 10 de junio de 1924, informa a los inspectores distritales de Socoroma y Parinacota prestar atención en la instrucción en las escuelas y determinar las intenciones electorales de los apoderados votantes.

En esta brecha, es paradigmática una nota confidencial enviada a las subdelegaciones por el gobernador Emiliano Bustos, señalando:

Sírvase convenientemente a los Directores de escuelas Públicas y particulares de esa subdelegación en el sentido de que deben concretar la enseñanza que dan solamente a los niños menores de 16 años, quedando prohibido enseñar a leer, escribir, o a firmar a aquellos que tengan más edad que de la indicada, que no sean chilenos netos. [Más adelante en el mismo oficio persuadía a que] por otra parte, es necesario tratar de que aprendan, aunque sea solo a firmar los chilenos netos de esa subdelegación que no lo sepan hacer. Recomiendo especialmente a ustedes poner en práctica, desde luego esta medida. (Archivo de la Subdelegación de Putre 1923d).

La suerte entonces ya estaba echada para los indígenas aymaras que debían sufragar en el plebiscito. 


\section{1925: ENTRE LA VIOLENCIA Y EL SUFRAGIO}

Las versiones tradicionales exponen que los indígenas no participaron de los procesos electorales en el Perú como lo ha cuestionado Aljovín de Losada (2005); por lo tanto, situar a las comunidades andinas del área de Putre dentro de un formato electoral sería -bajo la óptica clásica-imposible de considerar en el proceso plebiscitario. Según estas premisas, los requisitos básicos estarían situados en el dominio de la lecto-escritura, lo cual, frente a una evidente población analfabeta, determinarían la imposibilidad de ejercer el derecho al sufragio a los indígenas, debido a la inexperiencia de estos en los formatos de participación cívica en el ejercicio de la ciudadanía política (Díaz, Ruz y Galdames 2011). Pero aquí cabe evaluar tales aseveraciones: ¿qué significó el plebiscito en términos de la praxis de infrapolítica e identidades nacionales para las comunidades indígenas de Putre, Socoroma, Parinacota y Caquena?

Sobre este tema es necesario contextualizar el escenario sociopolítico de Arica y Tacna para la segunda década del siglo XX. En 1925, se aprobó el "Protocolo de Arbitraje y Acta Complementaria"', instituyéndose los requisitos fundamentales para los votantes en el Plebiscito programado para 1926. El árbitro norteamericano estimó que los requisitos electorales serían los siguientes:

A. Los varones de 21 años que sepan leer y escribir, que reúnan los requisitos de las siguientes clasificaciones numeradas $1^{\mathrm{a}}, 2^{\mathrm{a}}$ y $3^{\mathrm{a}}$.

$1^{a}$. Personas nacidas en Tacna y Arica y en las zonas aledañas.

$2^{\text {a. }}$. Los peruanos y chilenos que:

a. El 20 de julio de 1922 hubiesen tenido dos años de residencia continua en el territorio.

b. Continúen residiendo en la misma forma en el territorio hasta la fecha de la inscripción.

c. Que residan tres meses que precedan inmediatamente a la fecha de la inscripción, en la subdelegación en que tengan su residencia establecida al tiempo de inscribirse.

d. Que suscriban una declaración jurada respecto a su residencia, según modelo que suministraría la Comisión plebiscitaria.

$3^{\text {a }}$. Los extranjeros que cumplan con los requisitos de residencia.

3 “Documentos relativos al Plebiscito de Tacna y Arica, Calificación de los votantes", 1926, S/f. Sin edición. 
B. (1) Se establece que a nadie se le debe negar el derecho de voto en el Plebiscito por el solo hecho de no saber leer y escribir, si se trata de personas que el $20 \mathrm{de}$ julio de 1922 fuesen propietarias de bienes raíces en el territorio ${ }^{4}$.

En trabajos previos hemos discutido que la situación de la población andina en términos de instrucción pública era precaria (Díaz, Galdames y Ruiz 2010); por lo tanto, pese a la condición de analfabetismo, su integración al universo de votantes para 1926 consignaba que los ciudadanos que poseían propiedades y pagaban contribuciones, podían participar del evento electoral, como ya había acontecido durante el período peruano. Esta materia concilió el acuerdo de las fracciones, considerando que un número no menor de campesinos tanto chilenos como peruanos estaban en igualdad de condiciones. Si es así, entonces es necesario explicar la situación de la propiedad en el área de Putre ad portas de las votaciones. En 1925, la delegación peruana utilizando los índices de avalúos fiscales chilenos, presentó ante la "Comisión Plebiscitaria" los detalles sobre el valor de las propiedades:

\section{Cuadro No 2}

Rol de avalúos de la propiedad inmueble de la provincia de Arica (1924-1925)

\begin{tabular}{|c|c|c|c|c|}
\hline Jurisdicción & Lugar & Cantidad & & Pesos (\$) \\
\hline Puerto & Arica & 1.311 & Propiedad c/n valor de & 32.035 .500 \\
\hline \multirow{4}{*}{ Distrito } & Azapa & 263 & Propiedad c/n valor de & 2.278 .600 \\
\cline { 2 - 5 } & Lluta & 269 & Propiedad c/n valor de & 2.608 .100 \\
\cline { 2 - 5 } & Putre & 1.661 & Propiedad c/n valor de & 1.469 .254 .036 \\
\cline { 2 - 5 } & Gral. Lagos & 70 & Propiedad c/n valor de & 897.580 \\
\cline { 2 - 5 } & Codpa & 599 & Propiedad c/n valor de & 903.990 \\
\cline { 2 - 5 } & Belén & 164 & Propiedad c/n valor de & 575.900 \\
\hline
\end{tabular}

Fuente: Archivo del Ministerio de Relaciones Exteriores del Perú 1925: Cap. XI.

Resulta interesante la cantidad de propiedades inscritas en la localidad de Putre (1.661 propietarios), aspecto que confirma el intenso proceso de inscripción de tierras durante los primeros años del siglo XX, y al mismo tiempo, destacamos el valor de la pro-

4 "El sufragio femenino no existe en el Perú ni en Chile; ninguna de las partes lo ha pedido, ni ha sido sugerido en el curso de las negociaciones entre éstas. El saber leer y escribir es requisito para ejercer el derecho de sufragio en ambos países; pero, en vista de las circunstancias y de la que se tiene entendido respecto de la calidad de considerable parte de la población de las provincias, se cree justo no se exija este requisito a aquellos que poseen bienes raíces en el territorio" (Archivo del Ministerio de Relaciones Exteriores del Perú 1925: 57). El subrayado es nuestro. 
piedad, que era mucho más alto que en cualquier otro lugar de la provincia (Ruz 2009). Según el documento del Laudo, la mayoría de las propiedades de la subdelegación de $\mathrm{Pu}$ tre pertenecían a indígenas peruanos $(88,26$ por ciento), como se detalla a continuación:

\section{Cuadro No 3}

Rol de avalúos de la propiedad inmueble de la Subdelegación de Putre (1924-1925)

\begin{tabular}{|c|c|c|}
\hline Cantidad & & Pesos (\$) \\
\hline 1.466 & Propiedades de peruanos con valor de & 826.480 \\
\hline 42 & Propiedades de chilenos con valor de & 264.780 \\
\hline 132 & Propiedades de extranjeros con valor de & 357.634 \\
\hline 21 & Propiedades de fiscales con valor de & 20.300 \\
\hline 1.661 & Propiedades con valor de & $1.469 .254,36$ \\
\hline
\end{tabular}

Fuente: Archivo del Ministerio de Relaciones Exteriores del Perú 1925: Cap. XI.

No deja de sorprender la alta concentración de indígenas peruanos que poseen propiedades en la subdelegación (1.466). Por un lado, en el cuadro $\mathrm{N}^{\circ} 3$ se constata que cuando los indígenas inscriben tierras, como parte de un procedimiento legal en concordancia al aparataje jurídico del Estado chileno, al unísono se adscriben a la causa peruana, en un escenario beligerante. En términos porcentuales, la relación propiedad/ nacionalidad en la subdelegación de Putre fue la siguiente:

\section{Cuadro No 4}

Proporciones 1924-1925: nacionalidad/ propiedad porcentaje/valor

\begin{tabular}{|c|c|c|}
\hline Nacionalidad & En propiedad (\%) & En valores (\%) \\
\hline Peruanos & 88,26 & 56,25 \\
\hline Chilenos & 2,53 & 18,02 \\
\hline Extranjeros & 7,94 & 24,34 \\
\hline Fiscales & 1,27 & 1,39 \\
\hline & 100,00 & 100,00 \\
\hline
\end{tabular}

Fuente: Archivo del Ministerio de Relaciones Exteriores del Perú 1925.

Del mismo modo, al igual que el Rol de Avalúos, se realizó un censo el 15 de octubre de 1924, medición que sondeó las propiedades de la subdelegación de Putre, indicando como era de suponer que los peruanos poseían más tierras que los chilenos. En aquel censo se contemplaba informar sobre las condiciones de la tierra y el sitio donde se 
localizaban dichas propiedades; además, se precisaron antecedentes de los propietarios, similares datos registrados en los "censos sentimentales" realizados en los años anteriores. Las categorías incluidas en el Censo de 1924 fueron:
a) "propietarios peruanos"
b) "dudosos"
c) "peruanos que han hecho el servicio militar y tienen sentimientos chilenos"
d) "bolivianos"
e) "chilenos descendientes de peruanos"
f) "bolivianos que han hecho el servicio militar"
g) y "extranjeros"

La impresión que manejamos es la contradicción expresada por la población andina, la que inscribe tierras y participa ciudadanamente al amparo del Estado chileno, adscribiéndose identitariamente como peruanos.

A un año del plebiscito, el trabajo de las juntas inscriptoras en toda la provincia de Arica alcanzó la cifra de 3.332 electores, distribuyéndose en los distritos rurales de la siguiente manera:

\section{Cuadro No 5}

Electores en las comunidades del área rural de Arica (1924)

\begin{tabular}{|l|r|}
\hline \multicolumn{1}{|c|}{ Distrito } & No electores \\
\hline Lluta & 270 \\
\hline Azapa & 106 \\
\hline Belén & 107 \\
\hline Codpa & 111 \\
\hline Putre & 220 \\
\hline General Lagos & 64 \\
\hline Total electores & 878 \\
\hline
\end{tabular}

Fuente: Archivo del Ministerio de Relaciones Exteriores del Perú 1925.

Para la jornada electoral en las subdelegaciones rurales se concentraba un total de 878 electores, significando el 26,36 por ciento del universo de votantes del departamento de Arica, que en su área urbana concentraba el 73,64 por ciento. Este 26,36 por ciento del área rural constituía una cifra atractiva para los intereses peruanos, por lo que la preocu- 
pación de los propagandistas y la coacción de los agentes chilenos se manifestaron entre 1925 y 1926, desarrollándose intensos episodios de violencia (Díaz y Ruz 2003).

Volviendo al ámbito electoral, debemos señalar que los votantes inscritos en la provincia de Arica (y también en Tacna) de acuerdo al Reglamento Plebiscitario, se dividían en "nativos" y "residentes"; a estos últimos correspondería segmentarlos en tres subgrupos: peruanos, chilenos y extranjeros. La delegación peruana argumentó ante la comisión norteamericana que era inapropiada la inscripción de los electores, proponiendo la abstención de los votantes debido a la imposibilidad de materializar las mesas inscriptoras administradas directamente por la parte peruana. Se debe entender que los antecedentes electorales son producto de las mesas inscriptoras organizadas por la fracción chilena de cada subdelegación; por lo tanto, entre los datos de residentes se contempla mayoritariamente a chilenos y extranjeros. Así, de los 878 electores comprometidos con la consulta popular en el área rural, su desglose en nativos y residentes es:

\section{Cuadro No 6}

Electores de los distritos rurales según "nativos" y "residentes" (1924)

\begin{tabular}{|c|c|c|c|c|}
\hline Distritos & Nativos & Residentes chilenos & Residentes extranjeros & Total \\
\hline Lluta & 45 & 214 & 11 & 270 \\
\hline Azapa & 24 & 55 & 27 & 106 \\
\hline Belén & 90 & 4 & 13 & 107 \\
\hline Codpa & 96 & 5 & 10 & 111 \\
\hline Putre & 149 & 8 & 63 & 220 \\
\hline Gral. Lagos & 29 & 24 & 11 & 64 \\
\hline Total & 433 & 310 & 135 & 878 \\
\hline
\end{tabular}

Fuente: Archivo del Ministerio de Relaciones Exteriores del Perú 1925.

Estos datos muestran que en los valles de Azapa y Lluta la población residente alcanza una mayoría relativa sobre los nativos, probablemente por el grupo de gañanes, jornaleros, empleados u operarios del Ferrocarril de Arica-La Paz. En General Lagos, las condiciones de analfabetismo (68,1 por ciento), requisito primordial para el electorado y la presión sobre los indígenas en términos electorales, sumado a la injerencia de autoridades chilenas en la zona, permiten igualar relativamente los índices de nativos y residentes. La situación de Putre, Belén y Codpa es diferente, ya que es incuestionable la mayoría de nativos, antecedentes que la delegación peruana explica en los siguientes términos: 
las subdelegaciones de la sierra, Putre y Belén, presentan el fenómeno inverso... y la explicación está en que los pobladores de esos distritos son indígenas, y tienen relativa civilización y cultura, dedicándose perennemente a la guarda de sus pequeños intereses agrícolas y ganaderos, que trasmiten de padre a hijos (Archivo del Ministerio de Relaciones Exteriores del Perú 1925).

Además, la delegación peruana arguye que el alto grado de población extranjera, es decir bolivianos, se debía al temor de "muchos connacionales nuestros que indicaron tener dicha nacionalidad para estar cubiertos a la hostilidad chilena” (Archivo del Ministerio de Relaciones Exteriores del Perú 1925).

Respecto a los "nativos", las cifras entregadas por las mesas inscriptoras chilenas, y confirmadas por la Comisión plebiscitaria de 1924, muestran un total de 433 inscritos que representan el 49,31 por ciento del electorado; con la salvedad de que no incluye a "nativos" que fueron perseguidos y expulsados por las autoridades chilenas y que aparecen en los registros del Comité de Quejas, dirigido por el coronel Kregger hacia 1925. El desglose de la población "nativa” es:

\section{Cuadro No 7}

Número de residentes “nativos y no nativos" en las subdelegaciones rurales desde 1920

\begin{tabular}{|c|c|c|c|}
\hline Distritos & Nativos residentes desde 1920 & Nativos no residentes desde 1920 & Totales \\
\hline Lluta & 45 & -- & 45 \\
\hline Azapa & 24 & -- & 24 \\
\hline Belén & 90 & -- & 90 \\
\hline Codpa & 90 & 6 & 96 \\
\hline Putre & 147 & 2 & 149 \\
\hline Lagos & 26 & 3 & 29 \\
\hline Total & 422 & 11 & 433 \\
\hline
\end{tabular}

Fuente: Archivo del Ministerio de Relaciones Exteriores del Perú 1925.

Debido a las cercanías del plebiscito, las autoridades chilenas restringieron el libre tránsito por las provincias, bajo la excusa de mantener el orden público en todo el territorio. Una de las condiciones primordiales para viajar dentro de la zona y hacia el exterior consistía en poseer una "tarjeta de permiso" entregada por las autoridades, que eran exigidas en los retenes fronterizos de carabineros. Así consta para la zona de Tacna un decreto publicado en el periódico El Pacífico del 31 de julio de 1925, condicionando la movilidad por los senderos andinos a través de los siguientes preceptos: 
$1^{\circ}$ El tránsito de los viajeros del departamento de Arica quedan sujetos a las siguientes disposiciones.

$2^{\circ}$ Los habitantes de la subdelegación de Azapa, los habitantes de Livilcar, Humagata y puntos cercanos deberán obtener boletas del inspector del distrito.

$3^{\circ}$ Los que tengan sus domicilios en Molinos, Churiña y parte superior del valle viajarán por el camino que corre a lo largo del valle y solicitarán la boleta del inspector del distrito de Molinos o del retén de carabineros del mismo punto, debiendo avisar en el retén de carabineros de Poconchile.

$4^{\circ}$ Los habitantes de la Subdelegación de Putre que viajen a Putre o Arica, deberán obtener boleta en la forma siguiente:

a. Los habitantes de Caquena, Parinacota, Colpitas, Masahuento, Choquelimpie y demás puntos del distrito de Maranacota, del retén de carabineros más cercano a su residencia, debiendo entregarla o hacerla avisar en la tenencia de Putre.

b. Desde este punto seguirán el camino a Socoroma, siguiendo por la pampa y cuesta de Oxaya para bajar por el valle de Lluta por la quebrada de Chaquire, cerca de Molinos, y desde ese punto a Poconchile y Chinchorro.

c. Los habitantes del distrito de Putre y Socoroma seguirán el camino indicado en el inciso anterior.

d. Los habitantes de cualquier punto de la Subdelegación de Putre que se dirijan a la estación de Puquios deberán obtener boleta y hacerla visar en la tenencia de Putre y seguir el camino público recientemente construido que pasa por Jamirayo.

e. Los que se dirijan al paradero General Alcérreca procederán como se indica en la letra c), siguiendo el camino directo de Putre a dicho paradero.

$5^{\circ}$ Los habitantes de la subdelegación de Belén deberán obtener o visar la boleta en la forma siguiente:

a. Los de Chapiquiña, Murmutani, Sapabire, San Andrés de Pachama y puntos cercanos, del retén de carabineros de Chapiquiña, debiendo seguir el camino de Oxaya, Chaquire y Molinos, en su tránsito a Arica.

b. Los pueblos de Belén, de Tignamar, Saxamar, Guallatire, Chilcaya y Pampa de Laica, de la tenencia de carabineros de Belén, siguiendo en viaje a Arica el camino de la cuesta de Oxaya, Livilvar, Quebrada de Río Azapa, Alto Ramírez y retén de Lazareto.

$6^{\circ}$ Los habitantes de la Subdelegación de Codpa obtendrán la boleta en la tenencia del pueblo de Codpa, y seguirán el camino de Ofragia, Quebrada de Garza, Pampa del Atajo o Palo del Gringo, Quebrada Acho y Arica. 
$7^{\circ}$ El tránsito de Camarones o de las personas que lleguen a Tarapacá solo podrán hacerse por el camino de Camarones, presentándose al retén de dicho punto y siguiendo el camino indicado por los vecinos de Codpa.

$8^{\circ}$ Los habitantes de la Subdelegación del General Lagos obtendrán su boleta en los retenes de Carabineros más cercanos a su residencia y deberán visarlos en su tránsito al departamento de Tacna o a otras subdelegaciones de Arica, en la tenencia de Carabineros de Villa Industrial. El tránsito de la región del Mauri y de la frontera boliviana, deberá hacerse presentándose los viajeros a la tenencia de Visviri.

$9^{\circ}$ Las comunicaciones dentro de las subdelegaciones del General Lagos, Putre, Belén y Codpa o entre unas y otras de estas, se sujetaran a los que dispongan los subdelegados respectivos (El Pacífico 1925).

A esta medida panóptica debemos sumar otra disposición que requería informar a las agencias sobre el aumento (o disminución) de la población en las provincias, y la nacionalidad de los mismos. Dicha ordenanza fue tildada por la Comisión Plebiscitaria -presidida por Pershing- como el "decreto de alojamiento"s.

Estos dispositivos coaccionan el tránsito y alojamiento de los habitantes andinos, aumentando la vigilancia política sobre los comuneros. En noviembre de 1925, el subdelegado de Putre envió un oficio a los inspectores de los distritos de Socoroma y Parinacota, instruyendo que todos los documentos confidenciales relacionados con el plebiscito o con determinadas personas, deben ser destruidos o guardados con absoluto sigilo, prefiriendo su eliminación. De igual modo, indicaba que aquella misiva también debía ser eliminada, debido a la visita de agentes propagandistas peruanos. En consecuencia, se debían custodiar prolijamente los archivos (Archivo de la Subdelegación de Putre 1925).

El 24 de febrero de 1925, el teniente del censo envió al gobernador un informe estadístico, demostrando una alta presencia de ciudadanos peruanos en las aldeas tal como

$5 \quad \mathrm{Al}$ respecto se establecía que: 1. Los administradores de casa de huéspedes diariamente debían entregar a las jefaturas de Policía la lista de pasajeros de su responsabilidad, con las indicaciones contenida en un formulario proporcionados. Sin perjuicio que se pueda examinar por agente de policía en cualquier momento a manera de inspección. 2. Para las subdelegaciones rurales, las jefaturas de Policía tendrán un libro de registro de alojados, en el que se deben inscribir todos los hospedados. 3. Las autoridades sanitarias podrán visitar para inspección todas las casas de hospedajes; en las zonas rurales, estas se realzarán con el subdelegado y eventualmente el practicante. 4. Toda persona que recibe alojados tendrá un mínimo de 24 horas para dar cuenta a las autoridades competentes, asimismo si cambian de morada. 5. Cualquier infracción de las disposiciones será denunciada a la justicia ordinaria, sin perjuicio de las medidas que tome la autoridad. Cfr. (Archivo del Ministerio de Relaciones Exteriores del Perú 1925). 
registramos en los cuadros anteriores (Archivo de la Subdelegación de Putre 1925b). La intranquilidad de las autoridades chilenas se hizo sentir en los catastros y censos realizados periódicamente, elaborando carpetas con información referente a las tendencias de los ciudadanos de Putre que apoyaban a Perú (Archivo de la Subdelegación de Putre 1925b). Un informe similar se formuló el 14 de agosto de 1925, cuando el Sr. Alvino, capitán de corbeta y jefe de sección de extranjería chilena, exigió preocupado la pesquisa de los ciudadanos con derecho a voto en la Subdelegación de Putre (Archivo de la Subdelegación de Putre 1925b).

Para el 22 de octubre se demandó en Socoroma completar una ficha censal, registrando antecedentes sobre nacionalidad, propiedades y sentimientos de nacionalidad, fecha de nacimiento y ascendencia de cada uno de los socoromeños (Archivo de la Subdelegación de Putre 1925c). Los magros resultados censales llevaron a los agentes chilenos a desplegar diversas estrategias para intentar ganar el plebiscito. Una reacción ante tal diagnóstico fue la extrema vigilancia de los electores indígenas. Por ejemplo, el jefe de sección de extranjería chilena, el 14 de septiembre de 1925, acusó el recibo de una lista de ciudadanos a los que había que "observar sus sentimientos plebiscitarios". Al listado se adjuntó una nómina de ciudadanos a los que se exigían documentos de residencia y de propiedades (Archivo de la Subdelegación de Putre 1925b). Para noviembre, se entregaron instrucciones especiales para algunos casos; puntualmente, se emplazó al subdelegado de Putre a mantener cautela frente a los lugareños con evidentes sentimientos peruanos, a los que se les debía negar la carpeta de nacionalidad (Archivo de la Subdelegación de Putre 1925d).

Una segunda reacción fue abordar directamente casos conflictivos, instituyéndose el desplazamiento de ciudadanos peruanos lejos del lugar de litigio, so pretexto de ley de reclutamientos, desfiles o expulsiones de algunos líderes, como aconteció con el comunero de Putre Antonio Mollo (Díaz y Ruz 2003). Incluso, existieron situaciones donde se trasladaron comuneros desde Putre hasta Arica para manifestaciones de orden cívico chileno (Archivo de la Subdelegación de Putre 1925e). También, ocurrieron persecuciones a los activistas peruanos, los que fueron maltratados por chilenos, como aconteció con Marcos Analoca, campesino putreño, quien tras ser agredido, se refugió en el Ucayali, embarcación dispuesta por la Delegación peruana como centro de operaciones (Archivo del Ministerio de Relaciones Exteriores del Perú 1925).

El 12 de octubre, el subdelegado solicitó confidencialmente el acta de fundación de la "sociedad patriótica" de Putre (Archivo de la Subdelegación de Putre 1925e). Este tipo de organizaciones nacieron en Tacna, Arica, Iquique y la pampa salitrera con fi- 
nes xenófobos y represivos sobre el segmento poblacional peruano (González 2004a). El mismo subdelegado un mes antes había recibido de las autoridades ariqueñas un nuevo estandarte nacional para el pueblo y para que la organización lo utilizara (Archivo de la Subdelegación de Putre 1925e), al igual que banderas chilenas para poner a la venta (Archivo de la Subdelegación de Putre 1925f).

Debido a los actos de persecución en contra de los ciudadanos peruanos, el 2 de noviembre, la Comisión Plebiscitaria y la Delegación Norteamericana, encabezada por Pershing, dictaminó que varias autoridades chilenas debían ser removidas de sus cargos; entre ellos, el subdelegado de Putre (Archivo del Ministerio de Relaciones Exteriores del Perú 1925). Por el mismo motivo, el 21 de noviembre una nueva resolución de la Comisión resolvió remover a Carlos Quiroga, que era el oficial de Registro Civil de Codpa (Archivo del Ministerio de Relaciones Exteriores del Perú 1925), tensionando las relaciones diplomáticas, debido a que la parte chilena se rehusó a destituir a los funcionarios mencionados, al igual que al Intendente y al gobernador, los que igualmente habían sido acusados de actos xenofóbicos.

Sobre algunos hechos acaecidos en el poblado de Codpa, el periódico La Voz del Sur publicó la siguiente noticia: "Ernesto Vadulli y otros maleantes chilenos detienen en despoblados a tres peruanos que iban a Codpa. Uno formaba parte de la mesa de inscripción y elección que va a funcionar en aquel pueblo" (La Voz del Sur 1925). En tal sentido, los agentes chilenos, apoyados por grupos organizados como los Marzorqueros, los Cowboys, la Sociedad Patriótica, las Sociedades de Nativos y los Comités Cívicos ${ }^{6}$, desarrollaron una intensa campaña propagandística entre 1925 y 1926, intentado convencer

6 Los apelativos de cowboys y marzoqueros fueron expresiones elaboradas por los peruanos para identificar a los grupos xenófobos chilenos que durante la época de la violencia plebiscitaria (1925-1926), de forma reiterada agredieron a: simpatizantes peruanos, representantes de la Delegación Peruana Plebiscitaria, responsables o colaboradores de la Junta de Mesas Inscriptoras, como también a los propagandistas directo de la causa, especialmente a los trabajadores del periódico La Voz del Sur. De acuerdo a una entrevista realizada a una explebiscitaria, marzoquero era "porque cuando uno de ellos atacaba a los peruanos, no lo dejaban que solo ataque a uno, sino que se venían todos, toditos como mazorca, esa era la comparación", otra explebiscitaria precisaba acerca de la denominación de cowboys porque "andaban con sus tremendos sombreros, esos era pues los Cowboys que hacían las matanzas, desaparecían pues todo" (Manrique 1994: 45-54). De acuerdo con González (2004b), quien ha estudiado estos grupos para Tarapacá, sugiriendo que sería plausible pensar que la violencia ejercida por los Cowboys y Marzorqueros en Tacna y Arica culminaron afectando la imagen exterior del país, a la vez que facilitaron la estrategia peruana para declarar el plebiscito como inadmisible. Aquellos grupos patrioteros se organizaron a través de las Sociedades Nativas o Sociedad Cívicas, bajo la figura de clubes sociales. No es errado pensar, de acuerdo a la documentación revisada, que poseían nexos formales con las autoridades locales; lo anterior es confirmado por las pruebas expuestas por la Comisión Plebiscitaria (entre la que destacan la violencia ejercida en la localidad de Putre) que contribuyeron a declarar imposible la consulta popular. 
-incluso mediante el uso de la violencia- a los habitantes de las serranías y altiplanicies que se identificaban con la causa peruana. Ya el 21 de agosto de 1925, la Gobernación de Arica había notificado a todas las subdelegaciones que el Comité Cívico de Tacna y Arica realizaría un desfile patriótico, solicitando urgentemente el envío de personas de localidades rurales (Archivo de la Subdelegación de Putre 1925g). No obstante, en un ambiente irascible, el presidente chileno Arturo Alessandri demandó, el mismo 21 de agosto de 1925, enérgicas medidas contra cualquier incidente "antiplebiscitario" realizado por los agentes chilenos (Archivo de la Subdelegación de Putre 1925f). La copia del telegrama presidencial llegó a Putre tres meses después (Archivo de la Subdelegación de Putre 1925h).

El año 1926 se inicia con una intensa jornada de violencia. El 14 de marzo en Codpa, un grupo de chilenos dirigidos por José Tapia irrumpieron en la casa de Fortunata viuda de Chávez, vociferando que en esa vivienda años antes habían izado la bandera peruana. Los chilenos golpearon ferozmente a los moradores, resultando heridos Fortunata, además de Miguel Chávez, Fermín Chávez y Saúl Pozo; estos últimos ya habían sido agredidos por una turba de mazorqueros el 5 de febrero en Arica (Archivo del Ministerio de Relaciones Exteriores del Perú 1925). El 19 de marzo, el empleado peruano de la Junta de Inscripción de Codpa, Robustiano Chávez, al arribar a Arica con la correspondencia de los peruanos de aquella comunidad, fue atacado por ocho chilenos, los que después de golpearlo, lo arrestaron en la sección de investigaciones, requisando todos los escritos. Posteriormente, Robustiano fue amenazado por si delataba lo ocurrido (Archivo del Ministerio de Relaciones Exteriores del Perú 1925). El 2 de abril se hizo público el caso del socoromeño Bernardo Mamani Gutiérrez, de 60 años, campesino del pago de Aranche, quien al ser perseguido y golpeado por un grupo de chilenos, huyó herido desde la sierra para refugiarse en Arica (Archivo del Ministerio de Relaciones Exteriores del Perú 1925). Asimismo, otro socoromeño, Cleofe Pacaje, el 17 de mayo se quejó ante la Comisión Plebiscitaria de haber sido "apaleado" por unos "rotos" (Archivo del Ministerio de Relaciones Exteriores del Perú 1925).

En Putre, el subdelegado comunicó al gobernador en una misiva confidencial del 4 de marzo, que había comenzado la propaganda peruana, y para anularlos, instruyó a que ningún poblador debía venderles productos, o cobrarles un 100 por ciento más del valor original; por lo que la situación, aseguró, "estaba controlada" (Archivo de la Subdelegación de Putre 1926a).

Días antes, el mismo subdelegado había informado sobre incidentes provocados por propagandistas peruanos, alterando la normalidad de la convivencia en la comarca 
putreña (Archivo de la Subdelegación de Putre 1926b). Por otro lado, el 20 de marzo se denunció el caso de cuatro ciudadanos peruanos del valle de Lluta (Doroteo Marcelo Blanco, José Pérez, Manuel Cantella y Salomón Humire), quienes fueron incitados por el juez del poblado de Molinos a irse al sur de Chile. Contrariamente a la disposición del juez, los comuneros de Lluta decidieron refugiarse en Putre, sitio donde fueron apresados y maltratados. El informe diplomático señala que otro ciudadano peruano, Lorenzo Humire, por las mismas fechas desapareció extrañamente (Archivo del Ministerio de Relaciones Exteriores del Perú 1925).

Al respecto, el gobernador comunicó al subdelegado de Putre que el mayor Humberto Gordon viajaría en comisión electoral a la zona, tomando disposiciones y resoluciones relativas a las actividades electorales (Archivo de la Subdelegación de Putre 1926c); aleccionando este último a todos los subdelegados, inspectores, jueces y/o policías sobre sus acciones como autoridades frente al trato a los peruanos, evitando futuros incidentes y tensiones con el árbitro norteamericano (Archivo de la Subdelegación de Putre 1926c). No obstante, en Putre, los peruanos Amadeo Zarzuri y Pedro Huanca, y un boliviano de nombre Aquino, acusaron a la Comisión Plebiscitaria que estando pastando sus ganados en el potrero Intini, fueron víctimas de unos chilenos encabezados por José Benedicto Mazuelos, quienes los "agredieron, amarraron y flagelaron", además de robarles el ganado (Archivo del Ministerio de Relaciones Exteriores del Perú 1925).

Los hechos registrados constituyen un balance que forma parte de un informe del $1^{\circ}$ de mayo de 1926, el cual fue presentado a la Comisión Plebiscitaria a través del Comité de Quejas. Pero, los hechos de violencia en los sectores andinos continuaron. El periódico La Voz del Sur, señaló que una banda de chilenos prendieron fuego a la casa del peruano Agustín Córdova, situada en Alto Ramírez en el valle de Azapa. También expone que asaltaron la hacienda de Juan de Dios Cornejo que se encontraba en el Pago de las Ánimas. Todos estos vejámenes, comenta el periódico, demuestran la absoluta falta de garantías, de seguridad y progreso de Chile en toda la zona en litigio (La Voz del Sur 1926). En el mismo ejemplar, se indica que los chilenos han construido un ambiente de intimidación y terror en la provincia, puesto que no existe día en que no se realicen atropellos contra la población peruana. La noticia termina señalando que dos profesoras chilenas, Carolina Echevarría y Ernestina de Varela, mortifican a otras mujeres peruanas insultándolas y arrojándoles piedras (La Voz del Sur 1926). 


\section{TESTIMONIOS DE VIOLENCIA EN LOS ANDES. 1925 Y 1926}

El 23 de mayo de 1925, carabineros apostados en Codpa notificaron a 33 peruanos propietarios para que se presentaran al cuartel con el objetivo de enviarlos a "las pampas de Tarapacá". El subdelegado Cubillos y el teniente Délano, quedaron a cargo de conducirlos al poblado salitrero de Zapiga por la quebrada de Camarones. La mayoría de aquellos deportados fueron contratados como obreros en la oficina Patria. Tiempo después, un grupo reducido de campesinos logró burlar la vigilancia de la policía circunscrita al cantón salitrero, regresando a Codpa, como aconteció con Juan Bautista Sosa, el que habiendo sido internado en las oficinas Patria y Asturias, el 12 de diciembre de 1925 huyó caminando desde Zapiga a Arica presentándose a la Delegación Peruana (Archivo del Ministerio de Relaciones Exteriores del Perú 1925). El 11 de marzo de 1926 se formalizó la denuncia de Sosa, testimoniando la condición de secuestrados en la cual se encontraban los peruanos en la pampas salitrera (Archivo del Ministerio de Relaciones Exteriores del Perú 1925). Fue tan llamativo el caso de los codpeños, que los observadores norteamericanos se trasladaron al pueblo de Codpa a indagar sobre los detalles de este caso (Archivo del Ministerio de Relaciones Exteriores del Perú 1925).

Otros peruanos expulsados desde la sierra de Huaylillas o del altiplano ariqueño, fueron obligados a dirigirse a Bolivia, como aconteció con Manuel Flores, Rafael Tancara y Daniel Flores, quienes comunicaron los atropellos vividos en los primeros meses de 1925:

Charaña, abril 10 de 1925

Ministro Peruano. La Paz

Comunicamos V. E. que el terrorismo de carabineros chilenos en Cosapa, Cosapilla, Caquena, jurisdicción Arica, continúan con mayor violencia y cinismo. Somos víctimas de allanamientos a las casas, violación de nuestras mujeres en nuestra presencia, prisiones arbitrarias, despojo de dinero, alhajas y animales. Solicitan por medios violentos exhibición de títulos de nuestras propiedades para impedirnos derecho al voto plebiscitario. Con tales atropellos y agresiones, nos obligan a abandonar los hogares en compañía de esposas, hijos, para refugiarnos en la frontera boliviana, al margen del río Caquena, a la intemperie, huyendo de torturas, prisión después dos días sin alimentos.

Rogamos pedir nuestro Gobierno solicite garantías a nuestras vidas y las de nuestras familias. Respetuosamente. 
Manuel Flores Rafael Tancara Daniel Flores

(Archivo del Ministerio de Relaciones Exteriores del Perú 1925)

Otros casos describen la misma situación. A saber, el 26 de marzo fueron embarcados en el vapor América con destino a Iquique 87 peruanos de las "aldeas rurales", después de haber sido encerrados hasta completar este número y transportados por el ferrocarril de La Paz (Archivo del Ministerio de Relaciones Exteriores del Perú 1925). Se informó durante el mismo mes, que familias peruanas habían sido expulsadas por las autoridades chilenas y obligadas a cruzar la frontera hacia Bolivia, adonde habían llegado en "estado miserable", arreando sus ganados, como les sucedió a las familias Quequesana, Honores, Flores, Ticona, Zarzuri, Blas Flores, Calisaya, Cruz, Zamora, Quispe, Mamani, Alabe, entre otras (Archivo del Ministerio de Relaciones Exteriores del Perú 1925).

Frente a tales testimonios, el Comité de Quejas de la Comisión Plebiscitaria llegó a variadas conclusiones; entre ellas, el establecimiento de los victimarios y las formas que tomaban dichos actos de "terrorismo público", como la "desaparición”, “asesinato", "deportaciones", "asalto callejero" y "hostilidad callejera”. Sobre los lugares donde se cometían actos violentos, el Comité de Quejas señaló que no tan solo se realizan en las ciudades de Tacna y de Arica, sino también en los apartados distritos interiores. Reflejan el estado social de los distritos que colindan al norte con la frontera peruana, los sucesos de Challaviento... y reflejan, así mismo, el estado social de los distritos que separan a Arica de Tarapacá, al sur de aquel puerto, los atropellos de Putre, enumerados por el general Lassiter en su discurso sobre la impracticabilidad del plebiscito, y los atropellos de Codpa (Archivo del Ministerio de Relaciones Exteriores del Perú 1925).

En marzo de 1926 se expusieron al presidente de la Comisión Plebiscitaria una serie de quejas por los atropellos que estaban sufriendo los habitantes de Putre. Dichos actos generaron el nombramiento de un examinador cuyo propósito era investigar las acusaciones, para lo cual tomó declaraciones en Arica y audiencias en Putre, utilizando fuentes peruanas como chilenas. El informe compiló una serie de declaraciones que detallaban los acontecimientos, relevando nombres, fechas y lugares donde se cometieron abusos en contra de los aymaras peruanos. El examinador presentó el documento a la Comisión a través de la Comisión de Quejas. Bastará con reproducir consiguientemente los subtítulos del documento que grafican la situación de la población del área de Putre.

1. Notoria oposición de los carabineros al regreso de los electores peruanos. 
2. Flagelaciones brutales a los electores peruanos que regresaban a la zona, a los miembros de sus familias y a los simpatizantes de la causa peruana, por los carabineros y los propagandistas chilenos.

3. Prohibición de cualquier clase legítima de propaganda peruana por medio de espionaje y la intimidación llevada a tal extremo que la gente de Putre no se atrevía a hablar a los electores peruanos que regresaban o al personal peruano de la Junta de Inscripción y Elección.

4. Prohibición a los peruanos de usar su bandera.

5. Confiscación de las propiedades de los peruanos que regresaban a la zona.

6. Omisión de parte de las autoridades locales para castigar a los actores de estas ofensas.

7. Participación de las autoridades chilenas en Putre en actos de "terrorismo" e intimidación (Archivo del Ministerio de Relaciones Exteriores del Perú 1925).

Es necesario comentar que los hechos registrados por el examinador fueron oportunamente corroborados por las evidencias que poseía la Comisión Plebiscitaria, antecedentes que daban cuenta de los atropellos contra los electores indígenas peruanos (Archivo del Ministerio de Relaciones Exteriores del Perú 1925).

\section{CONCLUSIONES}

Los eventos electorales (incluidos el plebiscito como mecanismo de participación comunitaria) se constituyen como ritos cívicos colectivos que permiten a la ciudadanía participar activamente en los comicios para la elección de sus autoridades o decidir sobre ciertas políticas que los atañen. Consiguientemente, es la materialización de la ciudadanía al ser un evento que congrega a todos por igual. Si es así, ¿̨por qué entonces los indígenas aymaras hacia la década de 1920 se mostraron a favor del Perú para el comentado plebiscito, a pesar de que participaban activamente de todos los dispositivos desplegados por el Estado chileno: escuela, administración, reclutamiento militar?

Ciertamente, las comunidades indígenas andinas se vincularon con el Estado chileno como antes ya lo habían realizado con la República peruana, participando de las estructuras políticas imperantes. Pero al parecer, el tema más sensible se concentraba en las identidades nacionales circulantes en toda la región. Como ya hemos insistido, los indígenas aprovecharon los recursos que Chile les entregó; sin embargo, a la hora de asumir un compromiso ciudadano simbolizado en el voto, estos manifestarían su lealtad en favor del Perú, debido a que la construcción ciudadana está matizada por la intervención 
política, y aquella participación estaba ligada directamente al evento plebiscitario (Díaz, Ruz y Galdames 2011). Las cifras analizadas profusamente afirman esta tendencia: en el Censo de la Comisión Norteamericana de 1924, en Putre el 67,73 por ciento se declaró que votaría por el Perú; en General Lagos 45,31 por ciento; en Codpa el 86,48 por ciento y en Belén un 84,48 por ciento se adscribió a la identidad peruana. Es evidente que los indígenas durante el período reconocido como chilenización asumen una identidad peruana, en oposición a la chilena. Apelan a subjetividades como las emociones o sentimientos para manifestar sus compromisos identitarios reflejados en las fiestas públicas o en el escrutinio, pese a la violencia testimonial.

Desde un campo teórico, las identidades contienen tres funciones que permiten entender la tendencia de los aymaras en la cordillera andina de Arica. La primera función es la locativa, lo cual supone que la identidad permite a los sujetos (indígenas en este caso) autoubicarse y orientarse por referencia a las coordenadas del espacio social. También las identidades son selectivas, ya que provienen del carácter operativo de las representaciones sociales, lo cual significa que las identidades seleccionan en función de los valores que les son inherentes, el sistema de preferencias de los sujetos sociales, y también, por sus opciones prácticas en el campo delimitado por la posición social que ocupan. Por último, las identidades poseen la función integrativa, la que implica la posibilidad de integrar las experiencias del pasado con las del presente, en la unidad de una biografía incansable (tratándose de identidades individuales) o de una memoria colectiva compartida (tratándose de identidades colectivas) (Giménez 1994: 261), como acontece en el comportamiento de los electores de la zona de Putre, que apelan a la experiencia histórica peruana como un dispositivo integrador que se ve reformulado por el ritual cívico ciudadano, constituyendo la nueva oportunidad para imaginar la nación peruana en un escenario inimaginable en términos sociopolíticos.

Recapitulando, la frontera es el espacio semántico donde se cristalizan las identidades. Más allá del despliegue táctico de los Estados desde la metrópolis, es la comunidad indígena que en la periferia asume una postura identitaria ciudadana, que a su vez, fricciona el modelo chilenizador para concientizar a la población local. Durante el período estudiado, son los mecanismos identitarios los que se movilizarán entre las partes para graficar las intenciones de una comunidad indígena andina que desea ser protagonista en todos los detalles de la vida cívica en las comarcas.

En síntesis, en Putre y otras localidades alto andinas, durante los años de ocupación chilena surgieron actores locales intermedios que operaban en un formato de una infrapolítica diseminada específicamente en la vida cotidiana de los sujetos sociales andi- 
nos, con redes formales (y también informales) entre la comunidad y el Estado chileno, erigiendo discursos identitarios y praxis políticas múltiples y también contradictorias. Mientras aparecen, un día participando activamente en la organización administrativa chilena y otro izando banderas peruanas o en ocasiones representando a la comunidad ante las festividades religiosas; es decir, en un campo de negociación, una estrategia como resistencia al Estado chileno.

Ellos funcionarán como actores intermedios con diversos discursos, actuando en su praxis política como bisagras entre la comunidad y el Estado, reorientando híbridamente sus prácticas ante la nueva autoridad arriba en la cordillera.

\section{REFERENCIAS}

1. Aljovín de Losada, Cristóbal. 2005. "Sufragio y participación política. Perú: 1808-1896." Pp. 17-74 en Historia de las elecciones en el Perú, editado por Aljovín Cristóbal y López Sinesio. Lima, Perú: Instituto de Estudios Peruanos.

2. Anderson, Benedict. 2000. Comunidades imaginadas. Reflexiones sobre el origen y difusión del nacionalismo. México: Fondo de Cultura Económica.

3. Archivo General de la Nación. 1888. Prefectura del Departamento de Tacna, oficio nº 649.

4. Archivo Histórico Vicente Dagnino. 1917. Censo de Población de Arica. Arica: Dibam, Universidad de Tarapacá.

5. ----- 1904. Notas remitidas del Ministerio del Interior, oficio confidencial. Arica: Dibam, Universidad de Tarapacá.

6. ----- 1905 -1906. Subdelegados, folio No 59. Arica: Universidad de Tarapacá.

7. Archivo del Ministerio de Relaciones Exteriores del Perú 1925. Documentos sobre el laudo arbitral y los planteamientos de Kellogg, sobre la base de la información documental del canciller Pedro José Rada y Gamio. Lima, Perú.

8. Archivo de la Subdelegación de Putre. 1921. Oficios varios, s/n

9. ----. 1922a. Oficios varios, oficio nº 132, circular no 604 .

10. ----. 1922b. Oficios varios, oficio $\mathrm{n}^{\circ} 138$. 
11. ----. 1922c. Oficio confidencial, folio $31, \mathrm{n}^{\circ} 6$.

12. ----. 1923a. Oficio confidencial, oficios $n^{\circ} 62,63,64,65,66$ y 67.

13. ----. 1923b. Oficio confidencial, oficio $n^{\circ} 18$.

14. ----. 1923c. Oficios recibidos, oficio confidencial no 142.

15. ----. 1923d. Oficios confidenciales recibidos, oficio $\mathrm{n}^{\circ} 18,16$ de febrero.

16. ----. 1922-1923a. Oficios varios, folio $\mathrm{n}^{\circ} 118$, oficio confidencial $\mathrm{n}^{\mathrm{o}} 1225$.

17. ----. 1922-1923b. Oficios varios, folio $\mathrm{n}^{\circ} 118$, oficio confidencial $\mathrm{n}^{\circ} 8$.

18. ----. 1922-1923c. Oficio confidencial, folio $n^{\circ} 107$, oficio no 43

19. ----. 1922-1923d. Oficio confidencial, folio $\mathrm{n}^{\circ} 26$, oficio $\mathrm{n}^{\circ} 102$.

20. ----. 1924. Oficios recibidos, s/n.

21. ----. 1925a. Oficios varios, s/n.

22. ----. 1925b. Oficios varios, enero-diciembre, oficio s/n.

23. ----. 1925c. Oficios varios, enero-diciembre, ficha del Censo.

24. ----. 1925d. Oficios varios, enero-diciembre, oficio confidencial.

25. ----. 1925e. Oficios varios Libro Oficios e Informes secretos, oficio s/n.

26. -----. 1925f. Oficios de la Gobernación, oficio s/n

27. -----. 1925g. Oficios de la Gobernación, oficio confidencial.

28. ----. 1925h. Libro Oficios e Informes secretos, oficio s/n.

29. ----. 1926a. Oficios varios, folio nº 6.

30. ----. 1926b. Registros informes, telegrama.

31. ----. 1926c. Registros informes, oficio, s/n. 
32. Barceló, Luis. 1924. Appendix to the counter-case of the Republic of Chile. Documentos presentados por el Estado chileno al árbitro norteamericano, s/i. Santiago: Gobierno de Chile.

33. Calderón, Félix. 2000. La otra historia. El Tratado de 1929. Perú: Fondo Editorial del Congreso del Perú.

34. ----. 2006. Chilenización y Comunidad Andina. Escuela, Reclutamiento Militar y Articulaciones en Putre (1883-1929). Tesis para optar al grado de Magíster en Antropología Social, Universidad Católica del Norte, San Pedro de Atacama, Chile.

35. Díaz, Alberto, Rodrigo Ruz y Luis Galdames. 2011. "Participación de la población indígena en la política y justicia comunitaria en Arica y Tarapacá durante el siglo XIX." Estudios Históricos - Jurídicos 33: 511-32.

36. Díaz, Alberto, Luis Galdames y Rodrigo Ruz. 2010. Nación e identidad en los Andes. Indígenas de Arica y el Estado chileno (1883-1929). Arica: Ediciones Universidad de Tarapacá.

37. Díaz, Alberto y Rodrigo Ruz. 2003. "Cuando se agitaron las banderas. Conflicto y chilenización en la sierra ariqueña: el caso de Antonio Mollo (1901-1926)." Pp. 61-84 en Tarapacá. Un desierto de historias. siglos XIX-XX, editado por Macarena Gálvez, Alberto Díaz y Rodrigo Ruz. Arica: Ediciones Taller de Investigaciones Culturales TINCU.

38. ----. 2009. “Comuneros andinos en la administración chilena (Arica, 1880-1929)." Historia Social y de las Mentalidades 13 (2).

39. Documentos relativos al plebiscito de Tacna y Arica. 1926a. Exhortación pastoral que el Itmo. y Rvmo. Sr. Obispo de Arequipa dirige a los habitantes de Tacna y Arica y a cuantos deben acudir al Plebiscito que ha de decidir de la suerte de esas provincias.

40. Gellner, Ernest. 1983. Naciones y nacionalismo. Cambridge: University Press.

41. Giménez, Gilberto. 1994. "Modernización, cultura e identidades tradicionales en México.” Mexicana de Sociología 4: 255-72.

42. González, Sergio. 1994. "El Estado chileno en Tarapacá: El claroscuro de la modernización, la chilenización y la identidad nacional.” Diálogo Andino 13: 79-89.

43. ----. 2004a. El Dios Cautivo. Las ligas patrióticas en la chilenización de Tarapacá (19101922). Santiago: LOM Ediciones. 
44. ----. 2004b. "Patrioteros, nativos, mazorqueros y cowboys en el conflicto peruano-chileno por Tacna y Arica." Si Somos Americanos 6: 107-21.

45. -----. 2008. La llave y el candado. El conflicto entre Perú y Chile por Tacna y Arica. Santiago: LOM Ediciones.

46. Hobsbawn, Eric. 2002. La invención de la tradición. Barcelona: Editorial Crítica.

47. Gundermann, Hans. 1998. "Comunidad aymara, identidades colectivas y Estados nacionales en los albores del siglo XX.” Pp. 153-82 en A 90 años de los sucesos de la Escuela Santa María de Iquique, editado por S. González. Santiago: LOM - DIBAM - Centro de Investigación Barros Arana y Universidad Arturo Prat.

48. Manrique, Frida. 1994. Cuando caen las buganvillas. Testimonios de ex -plebiscitarios. Lima, Perú: s/e.

49. Palacios, Raúl. 1974. La chilenización de Tacna y Arica 1883-1929. Perú: Editorial Arica.

50. Periódico El Pacífico, 31 de julio de 1925. Tacna.

51. Periódico La Voz del Sur, 17 de agosto de 1925.

52. -----. 12 de marzo de 1926.

53. Revista Mundial VI (279), 16 de octubre de 1925, Lima.

54. Ruz, Rodrigo. 2009. La tenencia de tierras comunales como fuente de conflicto en la precordillera de Arica. Putre (1854-1935), Tesis para optar al grado de Magíster en Antropología, Universidad de Tarapacá - Universidad Católica del Norte, Chile.

55. Vial Solar, Javier. 1900. Páginas diplomáticas. Santiago: Imprenta, Litografía y Encuadernación Barcelona.

56. Yepes, Ernesto. 1999. Un plebiscito imposible... Tacna-Arica 1925-1926. Perú: Ediciones Análisis. 